\title{
Type 2 Diabetes Phenotype in a Small Isolated Zapotec-Speaking Community in the Valley of Oaxaca, Southern Mexico
}

\author{
Bertis B. Little ${ }^{1,2}{ }^{*}$, Robert M. Malina1,2,3, Maria Eugenia Peña Reyes ${ }^{4}$, Christopher R. Tillquist², \\ Elizabeth 0'Brien'1, Richard A. Kerber ${ }^{1}$
}

${ }^{1}$ School of Public Health and Information Sciences, University of Louisville, Louisville, KY, USA

${ }^{2}$ Department of Anthropology, University of Louisville, Louisville, KY, USA

${ }^{3}$ Department of Kinesiology and Health Education, The University of Texas, Austin, TX, USA

${ }^{4}$ Posgrado en Antropología Física, Escuela Nacional de Antroplogía e Historia, México D.F., México

Email: *Bert.Little@Louisville.edu

How to cite this paper: Little, B.B., Malina, R.M., Reyes, M.E.P., Tillquist, C.R., O'Brien, E. and Kerber, R.A. (2020) Type 2 Diabetes Phenotype in a Small Isolated Zapotec-Speaking Community in the Valley of Oaxaca, Southern Mexico. Open Journal of Endocrine and Metabolic Diseases, 10, 117-135.

https://doi.org/10.4236/ojemd.2020.109012

Received: August 21, 2020

Accepted: September 26, 2020

Published: September 29, 2020

Copyright $\odot 2020$ by author(s) and Scientific Research Publishing Inc. This work is licensed under the Creative Commons Attribution International License (CC BY 4.0).

http://creativecommons.org/licenses/by/4.0/ (c) (i) Open Access

\begin{abstract}
Objective: To test the hypothesis that the type 2 diabetes mellitus (T2DM) phenotype in an indigenous population is characterized by proportionally short legs and obesity. Methods: Anthropometric characteristics were compared in females and males with T2DM $(n=20, n=8$, respectively) and without T2DM ( $\mathrm{n}=117, \mathrm{n}=93$, respectively). Factor analysis derived dimensions were regressed on T2DM in logistic regression. Results: Weight, sitting height ratio and hip circumference were significantly lower $(p<0.0001)$ in females, while waist: hip ratio was significantly higher among women and men with T2DM ( $\mathrm{p}<0.0001$ and $\mathrm{p}<0.008$, respectively). Arm circumference, triceps skinfold, arm muscle circumference, and right and left grip strength were significantly lower among T2DM women ( $<0.0001$ for each). Five rotated principal components accounted for $86.7 \%$ of the variance: muscular (grip) strength (29.6\%), body mass (27.9\%), central adiposity (10.7\%), body height $(9.3 \%)$, and trunk length (9.2\%). Regression of factors on T2DM status among females indicated muscle strength $(\mathrm{OR}=0.16,95 \% \mathrm{CI}: 0.04-0.71)$ and central adiposity ( $\mathrm{OR}=13.76,95 \% \mathrm{CI}$ : $3.80-49.83)$ were predictors of T2DM. In males, muscle strength $(\mathrm{OR}=0.28,95 \% \mathrm{CI}: 0.07-1.08, \mathrm{p}<0.06)$ and central adiposity significantly predicted T2DM (OR $=3.17,95 \%$ CI: $95 \%$ 1.11 - 9.04, p < 0.008). Conclusion: Reduced muscle strength/mass and increased central adiposity characterize the T2DM phenotype.
\end{abstract}

\section{Keywords}

T2DM Phenotype, Central Obesity, Sarcopenia, Grip Strength, Body 
Proportions

\section{Introduction}

The type 2 diabetes (T2DM) phenotype has evolved with obesity or excess body weight being, perhaps the earliest phenotypic marker [1] [2]. Elevated weightfor-height expressed as the body mass index (BMI) [3] was also associated with T2DM [4] [5]. Although an elevated BMI is commonly associated with excessive fatness, the BMI is not an indicator of body composition. Skinfold thicknesses and predicted percentage body fat, both indirect estimates of body composition, were also used in the context of T2DM in several earlier studies; percentage fat was higher in individuals presenting T2DM [6] [7]. Over time, height, waist and hip circumferences, the ratio of the two (waist: hip ratio) and the ratio of waist circumference to height (waist: height ratio) were incorporated into studies of T2DM to address the potential importance of the relative distribution of abdominal fat or central adiposity in contrast to excess mass or estimated relative body fatness per se. Evidence suggested an association between elevated waist-height and waist-hip ratios and T2DM [8]. Central adiposity estimated from the subscapular skinfold thickness was also a predictor of T2DM in the Tecumseh Study [9].

Although height did not consistently differ between T2DM and non-T2DM subjects, significantly shorter leg length (conversely, longer trunk length) was suggested in T2DM individuals [10]. Several large survey studies found leg length was significantly shorter among T2DM individuals [11] [12] [13] [14] [15]. Sitting height ratio or leg length ratio was used as the indicator of proportional differences (relative trunk or leg length). Reduced leg length and related indices are frequently linked to chronic nutritional deprivation in early childhood, which has also been associated with T2DM in later adult life [11]-[16].

The relative distribution of adipose tissue is a sex- and ethnic-specific phenotype [17], and some evidence suggests differentiation of T2DM by ethnic-specific criteria. For example, an East Asian T2DM phenotype was characterized by greater abdominal adiposity (higher waist circumference) despite a lower BMI, [18] while a Mexico City (Mestizo) T2DM phenotype included an elevated BMI and waist: hip ratio, increased body weight and thicker skinfolds [19]. Impaired glucose tolerance, a characteristic diagnostic of pre-diabetes and T2DM, was associated with proportionally short legs in Brazilian [15] [20], Chinese and American adults [21]. Shorter height and leg length and a decreased leg lengthto-height ratio were also associated with insulin resistance and T2DM in American Hispanics, Whites, and Blacks sampled in NHANES III [20].

In the context of the preceding, the purpose of the present study is to analyze predictors of T2DM in a small sample of indigenous adult females and males in southern Mexico whose childhoods were complicated by mild to moderate undernutrition [22]. 


\section{Methods}

School children, adolescents and adults resident in a rural Zapotec-speaking community were the focus of a survey in 2000 . The community was located about $23 \mathrm{~km}$ northwest of the city of Oaxaca de Juarez at an altitude of about $1640 \mathrm{~m}$ in the piedmont zone of the northern (Etla) branch of the Valley of Oaxaca in southern Mexico. Characteristics of the Valley and community over the course of our studies have been previously described [20]-[26]. Census figures indicated a population of 1939 in 2000. Although the population has a high proportion of Zapotec speakers, the majority is largely bilingual. The project was originally approved by the ethics committee at the Michigan State University. After initial contacts, permission for the study was granted by the community authorities. Each individual also granted permission to be measured and interviewed.

The community has been historically dependent upon subsistence agriculture with families working small plots of individually or communally owned land. About 90\% of household heads were full-time farmers in 1978 [27]. The proportion of full-time farmers had declined to about $30 \%$ by 2000 [28] [29] which reflected, in part, a breakdown in economic isolation. Some adults were now part-time farmers; other occupational activities included vendors, artisans, construction workers, and industrial workers which generally required daily travel to the city of Oaxaca de Juarez. Based on observations in 2000, daily household chores, work-related and subsistence activities, in addition to regular walking suggested moderately active lifestyles in women and moderately-to-vigorously active lifestyles in men. Daily chores involved primarily animal care and agricultural activities for men and household activities related to cleaning, washing and food preparation for women. In addition, many women produce corn tortillas for sale, and take them to homes.

\section{Sample Description}

In 2000, 417 adults were measured, including 262 females and 155 males. Selection of adults $>39$ years old and listwise deletion of missing values resulted in 137 females and 101 males with complete data on all variables of interest. T2DM subjects in the present analysis were alive at the time of the survey in 2000, but some had died sometime after the survey and before December 31, 2009. In a prior study of T2DM-related mortality 70 individuals were identified with the disease $(n=28)$ or had a constellation of clinical indicators (renal failure, cardiovascular disease, coma) that were imputed to be cases $(n=42)$ of T2DM-associated death [28]. Of the $70 \mathrm{~T} 2 \mathrm{DM}$ cases previously reported, 35 individuals with T2DM-ascribed deaths were represented among those surveyed in 2000, and complete anthropometric data were available for 28 subjects, 20 females and 8 males [28]. It is possible that some unknown proportion of the cases is present in the control (non-T2DM) group. If there are T2DM cases in the control group, the effect would be decreased magnitude and significance of group differences. The control group excluded three individuals who had diagnosed T2DM. Notably, in most populations $30 \%-40 \%$ of T2DM individuals are undiagnosed. 
Weight, height, sitting height, arm circumference, the triceps skinfold, waist and hip circumferences, and grip strength were measured during household surveys or at the community health center [30] [31] [32] [33]. Body weight was measured with a portable digital scale to the nearest 0.1 kilogram. All subjects were measured while wearing ordinary clothing with sweaters, sweatshirts, jackets, ornaments, and shoes removed. To allow for variation in the clothing worn, measured weights were adjusted by subtracting $1.0 \mathrm{~kg}$. Several older subjects wore traditional clothing which included a waist band; an additional $0.5 \mathrm{~kg}$ was thus subtracted from the measured weight.

Height was measured with a field anthropometer with the subject standing erect without shoes on a flat surface. Sitting height was measured with the subject sitting erect on a flat surface. A smooth, flat board was used to insure an even surface for the measurements. Intra-observer technical errors of measurement were $0.32 \mathrm{~cm}$ for height and 0.42 for sitting height. Leg length (sub-ischial length) was estimated as standing height minus sitting height. The BMI was estimated as weight $(\mathrm{kg})$ divided by height $\left(\mathrm{m}^{2}\right)$.

Waist circumference was measured at the minimal circumference between the lowest ribs and iliac crest, while hip circumference was measured at the maximum extension of the buttocks [34]. For the few women wearing traditional clothing, the waist band was lowered to locate the measurement level. Both measurements were taken over clothing; the tape was gently pulled tight to compress the clothing. Unfortunately, replicate measurements of both circumferences were not possible. The waist: hip and waist: height ratios were computed by simple division. Elevated waist: hip cutoff for females was $85 \mathrm{~cm}$ and 90 $\mathrm{cm}$ for men for categorical analysis.

Relaxed mid-arm circumference (metal tape, nearest $0.1 \mathrm{~cm}$ ) and the triceps skinfold (Lange caliper, nearest $0.5 \mathrm{~mm}$ ) were measured on the left side. Technical errors of measurement were $0.29 \mathrm{~cm}$ and $0.83 \mathrm{~mm}$ for arm circumference and the triceps skinfold, respectively. Arm circumference was corrected for the thickness of the triceps skinfold to provide an estimate of mid-arm muscle circumference (EAMC) of the left arm [35].

Grip strength of the right and left hands was measured with an adjustable dynamometer (Stoelting Smedley Hand Dynamometer, Stoelting Co., Wood Dale, IL) to the nearest $0.5 \mathrm{~kg}$ [36]. The dynamometer was adjusted to the hand size of each subject prior to testing; it was the setting with which the subject was comfortable. Subjects were encouraged to give a maximal effort with each trial. Three trials were given with each hand; trials were alternated between hands. The best trial with each hand was retained for analysis. Intraclass correlations among all trials with both hands ranged from 0.73 to 0.90 , and indicated acceptable within day reliability for group comparisons, although correlations were generally lower in females. The sum of right and left grip strength was expressed relative to weight (grip: weight ratio), while left grip strength was also expressed relative to EAMC (LG: EAMC ratio). 
Age as of the last birthday and/or date of birth was obtained from each subject at the time of measurement. For those who could not recall their birth date (primarily older adults), age as of last birthday was recorded and was indicated at mid-year [30] [31].

\section{Statistical Analysis}

Multivariate analysis of variance (MANOVA) and multivariate analysis of covariance (MANCOVA) were used to compare anthropometric characteristics and derived variables of the 20 women and 8 men who died of T2DM sometime after the anthropometric survey and the remaining 117 women and 93 men (non-T2DM) in the 2000 survey. Age was used as a covariate. The BMI was transformed into categorical variables: overweight $(\geq 25$ and $<30)$, obese $(\geq 30)$, and overweight plus obesity. Waist circumference was recoded to a binary variable $(0,1)$ categories; $>85 \mathrm{~cm}=1$ for females, and $>90 \mathrm{~cm}=1$ for males. The waist: hip ratio was transformed into a binary variable, $\geq 0.90$ vs. $<0.90$. Categorical variables were tested against T2DM status using Mantel-Haenszel chi-square.

Dimension reduction from 23 variables to five linear combinations (components) was done to facilitate statistical analysis and interpretation. Principal components analysis with varimax rotation was used to approximate the best linear fit to the data. Loadings (correlations of metric with the principal component $)<0.40$ were suppressed. The determinant was $1 \times 10^{-4}$, indicating a non-singular correlation matrix. Components with eigenvalues $\geq 1.0$ were retained as variables for analysis. Retained component variables were scaled in standard units (i.e., mean $=0$, standard deviation $=1.0$ ). Multiple logistic regression was used to evaluate the predictive value of the five principal components as independent (predictor) variables and T2DM (yes, no) as the dependent (target) variable. The five dimensions (components) were regressed on T2DM presence or absence in multivariate logistic regression analysis.

Small sample size ( $\mathrm{n}=20$ T2DM females and $\mathrm{n}=8$ T2DM males) is a major weakness of the analyses. A resampling technique was used for MANOVA, MANCOVA and logistic regression; PCA/factor analysis does not have a resampling option. Bootstrapping (simple Monte Carlo, $\mathrm{n}=10,000$ resamples with replacement) was done to mitigate the effect of small sample size on produce robust variance estimates. Notably, bootstrapping does not always increase significance as $p$ values increase in some instances. Age at menarche was assessed in a separate analysis using age matched pairs and a paired t-test.

\section{Results}

Descriptive statistics for all variables, measured and derived, in T2DM and non-T2DM women and men are summarized in Table 1.

Age-adjusted means and standard errors are also reported in Table 1 because age at the time of measurement differed significantly between T2DM and non-T2DM individuals ( 63.5 yrs. vs. 51.6 yrs., $\mathrm{p}<0.0001$ for females and 68.4 yrs. vs. 56.0 yrs., $\mathrm{p}<0.0001$, respectively). Age at menarche was not significantly 


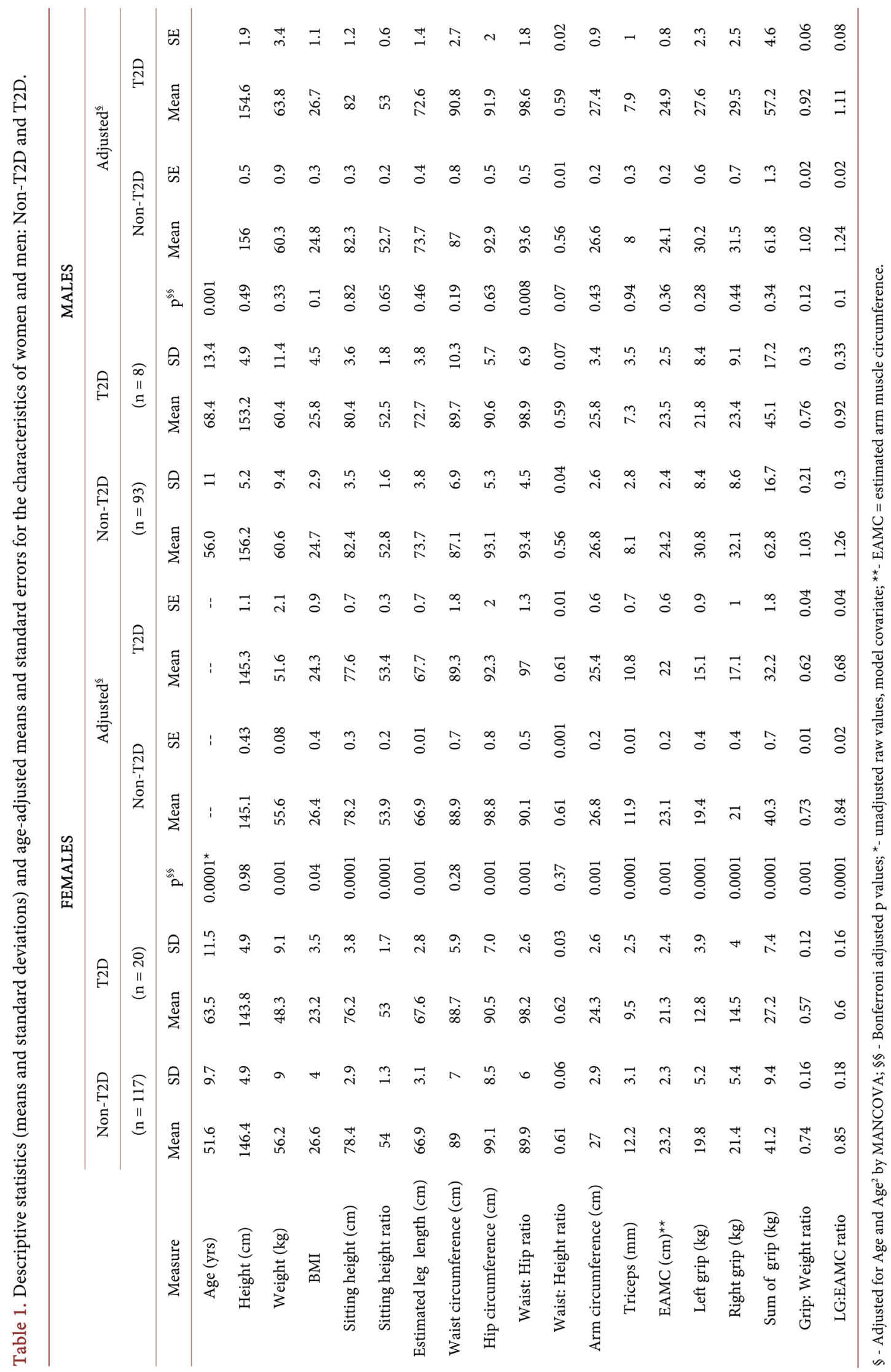


different between T2DM (14.3 yrs. $\pm 0.3 \mathrm{SE})$ and non-T2DM women (14.9 yrs. \pm $0.3)$. There was no significant difference in height between T2DM and non-T2DM women or men. Women with T2DM were, on average, $4.0 \mathrm{~kg}$ lighter than non-T2DM women $(\mathrm{p}<0.001)$. BMI was higher in non-T2DM women contrasted to T2DM females (26.4 v. 24.3, p < 0.04, respectively). Among T2DM men, BMI was 26.7 but lower (not significantly) among non-T2DM men (24.8). Sitting height was significantly $(\mathrm{p}<0.0001)$ different between T2DM and non-T2DM women, with T2DM females $0.6 \mathrm{~cm}$ shorter than non-T2DM. Sitting height was shorter among T2DM and non-T2DM men by $0.3 \mathrm{~cm}$, but the difference was not significant. Leg length was significantly $(\mathrm{p}<0.001)$ longer in females with T2DM compared to non-T2DM females $(0.8 \mathrm{~cm})$, but was shorter in T2DM males by $1.1 \mathrm{~cm}(\mathrm{p}<0.46)$ relative to non-T2DM males. The sitting height ratio was higher among non-T2DM women (53.9 vs 53.4, p < 0.0001), and T2DM compared to non-T2DM men (53.0 vs 52.7, NS). Hip circumference was higher in non-T2DM compared to T2DM women $(98.8 \mathrm{~cm}$ vs. $92.3 \mathrm{~cm}, \mathrm{p}<$ $0.0001)$ and men $(92.9 \mathrm{~cm}$ vs $91.9 \mathrm{~cm}$, NS), but waist circumference did not differ between groups of women and men. The waist:hip ratio was significantly higher among T2DM compared to non-T2DM women (97.0 vs 90.1, p $<0.0001$ ) and men (98.6 vs 93.6, p < 0.008). Triceps skinfold, arm circumference, estimated mid-arm muscle circumference, and grip strength and related ratios were significantly lower among T2DM women ( $<<0.001$ to $\mathrm{p}<0.0001$ ). The pattern in males was similar to that observed in females, except none of the differences are significant likely because of small sample size $(n=8)$.

Among females, the frequency of overweight was higher in the non-T2DM $(\mathrm{OR}=0.48)$, but was not significantly increased (Table 2$)$. Obesity was not present in the sample of T2DM females, but was higher in the non-T2DM group $(\mathrm{p}<0.04)$. Overweight plus obesity was significantly increased in frequency among non-T2DM individuals ( $\mathrm{OR}=0.25, \mathrm{p}<0.004)$. The frequency of a waist circumference $\geq 85 \mathrm{~cm}$ tended to be higher in T2DM individuals but was not significantly different between T2DM and non-T2DM women, nor were BMI (top tertile) or sitting height ratio (top tertile).

In males, the frequency of overweight did not differ between the groups ( $\mathrm{p}<$ 0.16). The tendency was for frequencies of obesity, overweight plus obesity, and waist circumference $>90 \mathrm{~cm}$, and BMI (top tertile) to be greater in T2DM compared to non-T2DM men. The waist: hip ratio (top tertile) was significantly increased in frequency among males with T2DM (OR = 9.52, 95\% CI: $4.80-50.46$, $\mathrm{p}<0.006)$.

The varimax rotated PCA (factor analysis) for the combined sample of women and men resulted in five components that accounted for $86.7 \%$ of variance (Table 3). The components included: 1) a muscle strength factor (27.9\% with loadings on EAMC, grip strength and its transforms at 0.90 or higher); 2) a body mass factor (27.9\%) with loadings on BMI and weight at 0.85 or higher; 3 ) a central adiposity factor (10.7\%) which was correlated with the waist: hip ratio 
(0.95), the top quintile of the waist: hip ratio (top quintile) (0.84); 4) a body height factor (9.3\%) which loaded high on height (0.70) and leg length (0.53); and 5) a trunk length factor (9.3\%) which loaded on sitting height ratio (top quintile) (0.87), and sitting height (0.85). This step was done to reduce dimensions (i.e., the number of variables) because the sample size is small. The PCA components are standardized, and for each 1.0 increase in an odds ratio (OR) equates to a 1.0 standard deviation increase (or decrease) for the factor.

Total Sample

In the genders combined sample, multivariate logistic regression of T2DM status on factor 1 indicated that increased muscle strength was protective against T2DM (OR = 0.19, 95\% CI: $0.09-0.39, \mathrm{p}<0.0001)$. Adiposity (factor 3 ) was associated with an increased propensity to have T2DM (OR =6.02, 95\% CI: 3.02 11.99, $\mathrm{p}<0.0001$ ). Body height (PC component 4) was predictive of T2DM (OR $=1.59,95 \%$ CI: $0.94-2.68, \mathrm{p}<0.03)$. The regression correctly classified $93.7 \%$ of cases with a pseudo $\mathrm{R}^{2}=0.29-0.56$. Taller individuals were usually taller with high central adiposity and reduced muscle strength compared to non-T2DM individuals.

Table 2. Cross tabulation analysis of T2D status by indicators of overweight and obesity.

\begin{tabular}{|c|c|c|c|c|c|c|}
\hline \multirow[b]{2}{*}{ Measure } & \multirow{2}{*}{$\begin{array}{c}\text { T2DM } \\
\mathbf{n}\end{array}$} & \multirow{2}{*}{$\begin{array}{c}\text { non-T2DM } \\
\text { n }\end{array}$} & \multicolumn{4}{|c|}{$95 \% \mathrm{CI}$} \\
\hline & & & OR & lo & hi & $\mathrm{p}$ \\
\hline FEMALES & $(n=20)$ & $(n=117)$ & & & & \\
\hline Overweight (OW) & 6 & 63 & 0.48 & 0.17 & 1.31 & 0.12 \\
\hline Obesity (OB) & 0 & 21 & -- & -- & -- & $0.04^{*}$ \\
\hline $\mathrm{OW}+\mathrm{OB}$ & 6 & 84 & 0.25 & 0.09 & 0.69 & 0.004 \\
\hline Waist circ. $>85 \mathrm{~cm}$ & 6 & 36 & 0.99 & 0.35 & 2.78 & 0.73 \\
\hline $\mathrm{BMI}^{\star *}$ & 2 & 34 & 0.32 & 0.07 & 1.47 & $0.08^{\star}$ \\
\hline Sitting height ratio $^{\star *}$ & 1 & 25 & 0.18 & 0.02 & 1.4 & 0.1 \\
\hline Waist: Hip ratio ${ }^{\star *}$ & 20 & 24 & & -- & & $0.0001^{\star} \S$ \\
\hline MALES & $(n=8)$ & $(n=93)$ & & & & \\
\hline Overweight (OW) & 3 & 38 & 0.92 & 0.21 & 4.06 & 0.16 \\
\hline Obesity (OB) & 1 & 35 & 3.29 & 0.32 & 33.51 & $0.27^{\star}$ \\
\hline $\mathrm{OW}+\mathrm{OB}$ & 4 & 42 & 1.29 & 0.3 & 5.45 & 0.73 \\
\hline Waist circ. $>90 \mathrm{~cm}$ & 4 & 33 & 1.91 & 0.45 & 8.13 & 0.39 \\
\hline $\mathrm{BMI}^{\star *}$ & 3 & 18 & 2.6 & 0.57 & 11.89 & $0.18^{\star}$ \\
\hline Sitting height ratio ${ }^{\star *}$ & 2 & 18 & 0.23 & 0.03 & 1.78 & $0.65^{\star}$ \\
\hline Waist: Hip ratio ${ }^{\star *}$ & 6 & 23 & 9.52 & 1.8 & 50.46 & 0.006 \\
\hline
\end{tabular}

${ }^{\star}$ Fisher's exact probability test, two tailed; ${ }^{\star *}$ Top quintile; $-\$$ empty cell. 
Table 3. Results of the principal components analysis of anthropometric and derived variables with varimax rotation of the factors: Genders combined.

\begin{tabular}{|c|c|c|c|c|c|}
\hline & \multicolumn{5}{|c|}{ Varimax Rotated Principal Components } \\
\hline & $\begin{array}{l}\text { Muscle } \\
\text { Srtength }\end{array}$ & $\begin{array}{l}\text { Body } \\
\text { Mass }\end{array}$ & $\begin{array}{c}\text { Central } \\
\text { Adiposity }\end{array}$ & $\begin{array}{r}\text { Body } \\
\text { Height }\end{array}$ & $\begin{array}{c}\text { Trunk } \\
\text { Length }\end{array}$ \\
\hline & 1 & 2 & 3 & 4 & 5 \\
\hline Sum right + left grip & 0.97 & & & & \\
\hline EAMC & 0.96 & & & & \\
\hline Left grip & 0.96 & & & & \\
\hline Right grip & 0.95 & & & & \\
\hline Grip/weight & 0.94 & & & & \\
\hline Sitting height & 0.58 & & & 0.55 & \\
\hline Age & -0.5 & & & 0.48 & \\
\hline BMI & & 0.95 & & 0.49 & \\
\hline Hip circumference & & 0.89 & & & \\
\hline Waist circum. & & 0.87 & & 0.41 & \\
\hline Weight & 0.4 & 0.85 & & & \\
\hline Arm circumference & & 0.85 & & & \\
\hline BMI (top quintile) & & 0.75 & & & \\
\hline Waist: height ratio & -0.4 & 0.73 & & & \\
\hline Arm muscle circ. & & 0.72 & & 0.41 & \\
\hline Triceps skinfold & & & & & \\
\hline Waist: hip ratio & & 0.56 & 0.95 & -0.47 & \\
\hline Waist: hip ratio (top quintile) & & & 0.84 & & \\
\hline Height & 0.65 & & & 0.7 & 0.68 \\
\hline Leg length & 0.53 & & & 0.63 & -0.51 \\
\hline Sitting height ratio (top quintile) & & & & & 0.87 \\
\hline Sitting height ratio & & & & & 0.80 \\
\hline$\%$ variance & 29.6 & 27.9 & 10.7 & 9.3 & 9.2 \\
\hline Eigenvalue & 6.5 & 2.4 & 2.0 & 2.0 & \\
\hline
\end{tabular}

Total $=86.7 \%$ of variance explained.

\section{Females}

Among females, multivariate logistic regression analysis of T2DM status on the five PC's components (factors) indicated three significant predictors of T2DM status: muscle strength, central adiposity, and body height (Table 4). High grip strength $(\mathrm{OR}=0.16,95 \% \mathrm{CI}: 0.04-0.71)$ was protective from T2DM, high central adiposity (OR $=13.76,95 \% \mathrm{CI}: 3.80-49.03)$ predicted diabetes, and taller body height $(\mathrm{OR}=4.61,95 \% \mathrm{CI}: 1.20-17.73)$ predicted diabetes status. The regression model correctly classified $91.2 \%$ of subjects and accounted for as much as $69 \%$ of variance according to pseudo $R^{2}$ values $\left(R^{2}=0.39-0.69\right.$; Table 4). 
Table 4. Logistic regression analysis of principal components (from Table 2) with T2DM as the dependent variable.

\begin{tabular}{|c|c|c|c|c|c|}
\hline & \multicolumn{5}{|c|}{ 95\% Confidence Interval } \\
\hline & OR & lo & hi & $\mathbf{p}$ & $p^{s}$ \\
\hline \multicolumn{6}{|c|}{ GENDERS COMBINED } \\
\hline Muscle strength & 0.19 & 0.09 & 0.39 & 0.0001 & 0.001 \\
\hline Body mass & 0.65 & 0.36 & 1.15 & 0.14 & 0.21 \\
\hline Central adiposity & 6.02 & 3.02 & 11.99 & 0.0001 & 0.001 \\
\hline Body height & 1.59 & 0.94 & 2.68 & 0.03 & 0.02 \\
\hline Trunk length & 0.87 & 0.5 & 1.53 & 0.63 & 0.58 \\
\hline \multicolumn{6}{|l|}{ FEMALES } \\
\hline Muscle strength & 0.16 & 0.04 & 0.71 & 0.02 & 0.02 \\
\hline Body mass & 0.51 & 0.23 & 1.13 & 0.1 & 0.14 \\
\hline Central adiposity & 13.76 & 3.8 & 49.83 & 0.0001 & 0.001 \\
\hline Body height & 4.61 & 1.2 & 17.73 & 0.03 & 0.02 \\
\hline Trunk length & 0.79 & 0.29 & 2.11 & 0.63 & 0.57 \\
\hline \multicolumn{6}{|l|}{ MALES } \\
\hline Muscle strength & 0.28 & 0.07 & 1.08 & 0.06 & 0.09 \\
\hline Body mass & 1.02 & 0.33 & 3.09 & 0.98 & 0.86 \\
\hline Central adiposity & 3.17 & 1.11 & 9.04 & 0.03 & 0.008 \\
\hline Body height & 1.07 & 0.22 & 5.13 & 0.94 & 0.82 \\
\hline Trunk length & 0.93 & 0.45 & 1.9 & 0.84 & 0.71 \\
\hline
\end{tabular}

sp value is bootstrapped 1000 resample; Cox-Snell $\mathrm{R}^{2}=0.39$ and 0.15 , females and males, respectively; Nagelkerke $\mathrm{R}^{2}=0.69$ and 0.36 , females and males, respectively; $91.2 \%$ and $95 \%$ correctly classified, females and males, respectively.

\section{Males}

Among males, muscle strength (factor 1$)$ was protective against $\mathrm{T} 2 \mathrm{DM}(\mathrm{OR}=$ $0.28,95 \%$ CI: $0.07-1.08, p<0.09)$, indicating lower strength was associated with T2DM. Central adiposity (factor 3) was a significant predictor of T2DM among males $(\mathrm{OR}=3.17,95 \% \mathrm{CI}: 1.11-9.04, \mathrm{p}<0.008)$, indicating increased fatness was predictive of diabetes. Pseudo $\mathrm{R}^{2}$ ranged from 0.15 to 0.36 , and $95 \%$ of cases were correctly classified using this regression model in the sample of 8 T2DM males (Table 4). Bootstrapping did not substantively change the results.

\section{Discussion}

The comparison of the anthropometric characteristics of indigenous Zapotec women and men with and without T2DM indicated significant differences. Women with T2DM had, on average, an increased waist: height ratio and reduced weight, BMI, sitting height ratio, hip circumference, triceps skinfold, and grip strength compared to women without T2DM. T2DM men had significantly 
higher waist: hip ratio compared to males without T2DM. The lack of significance in other measures was likely due to small sample size (Type II statistical error). Age at menarche has been reported to be lower among women with T2DM [37], but was not significantly different between T2DM and non-T2DM women. Nonetheless, T2DM women tended to have a lower age at menarche ( $\mathrm{p}$ $<0.14$ ). Using dimension reduction, three significant generalized components of the T2DM phenotype were indicated by factor analysis for females: 1 ) decreased strength and muscularity (grip strength and arm muscle circumference measurements), 2) increased central adiposity (waist circumference, waist: hip ratio, waist: height ratio) in T2DM compared to non-T2DM women, and 3) increase in height due to longer leg length. The consensus T2DM phenotype components appear to be sarcopenia and central adiposity in indigenous women and men (Table 4).

In several prior investigations, an increased sitting height ratio and decreased leg length were associated with the risk for T2DM [11]-[16] [20] [37]. Shorter legs and increased sitting height ratio were interpreted as suggesting early childhood deprivation in these studies because leg length is a sensitive indicator of chronic marginal health and especially nutritional conditions in children $<5$ years of age. Childhood deprivation is an apparent trigger for T2DM [38]. In the present analysis, age adjusted height did not differ between the T2DM and non-T2DM women or men. Leg length was significantly greater and the sitting height ratio was lower in the women with T2DM, which contrasted published data. On the other hand, estimated leg length tended to be shorter in the small sample of T2DM men, and siting height ratio was slightly higher, but not significantly.

The present study was consistent with a prior study of T2DM in the Valley of Oaxaca regarding increased waist: hip ratio; however, Zapotec women with T2DM in the earlier study had an increased BMI compared to non-T2DM individuals [39]. Individuals in the present study had a lower BMI. Note, however, subjects in the present study were surveyed in 2000 and died $<10$ years after the survey. Women in the Escobedo et al. [39] study were not followed to assess mortality. Thus, T2DM subjects in the present study may have a more advanced form or stage of the disease as suggested from the presence of sarcopenia inferred from muscle strength and arm muscle circumference as they did die $<10$ years from the time of the anthropometric survey. Perhaps the apparently "accelerated age-associated loss" of muscle mass (EAMC) and function (strength) observed in the present study was associated with advanced T2DM. In addition, reduced hip circumference among T2DM women may also indicate loss of muscle mass as the gluteus maximus muscle complex is the major component of the circumference. Neither grip strength nor limb muscle circumferences were reported in the other study of Zapotec women [39]. Frailty, assessed from sarcopenia, was also associated with elevated risk for mortality among T2DM individuals [40] [41]. T2DM women in the present study had apparent signs of ac- 
celerated aging, i.e., sarcopenia. With few exceptions, characteristics of the small sample of males with T2DM in the present study were generally consistent with those of females with T2DM.

Sarcopenia refers to age-associated loss of muscle mass and function, although a certain amount of muscle loss with advancing years is "normally" expected. Among individuals with T2DM, loss of muscle strength and mass exceeded the expected age-associated loss of muscle mass and function in non-T2DM individuals [40] [41] [42]. Poorly controlled glucose levels are associated with greater muscle mass and functional loss, compared to good glycemic control [43]. Chronic kidney disease (CKD), a common comorbidity in advanced age T2DM individuals, is associated with accelerated and more severe sarcopenia than among T2DM individuals without CKD [44]. Among Hispanic Americans, the rate of sarcopenia was apparently greater than in non-Hispanic American Whites [44]. In the indigenous Zapotec population, the age-associated decrease in muscle strength was not linear across ages (19 to 89 yrs.); the slope increased significantly in males and females older than 40 - 49 years [36]. Estimated muscle mass and strength were decreased among Zapotec women and men with T2DM compared to non-T2DM women and men, even after adjusting for age and age $^{2}$; the results were similar to previously reported findings [40] [41] [42]. Importantly, frailty (loss of muscle mass and function) is a strong predictor of mortality [45] [46].

Observations for indigenous Zapotec women and men who died of T2DM and/or related conditions in southern Mexico contrast with the commonly observed T2DM phenotype in populations of US Whites, African-Americans and Hispanics which included increased overweight and obesity, and an increased sitting height ratio [20]. Increased height was protective against T2DM, while increased weight and BMI were risk factors for T2DM in northern Europeans [46]. A common cliché in the general clinical literature is that $90 \%$ of individuals with diabetes are obese (or overweight) and that $10 \%$ of the obese (or overweight) population is diabetic [47]; this appears to characterize the European T2DM phenotype. However, T2DM individuals in the present investigation may have a more advanced form of the disease than subjects in prior studies because they died $<10$ years from the time they were measured in 2000 .

Comparisons of the BMI across ethnic groups suggested a propensity for T2DM with an elevated BMI among individuals with T2DM, except for Asians among whom the BMI was not elevated [48] [49]. T2DM was associated with a lower BMI among individuals of Asian ancestry. T2DM among Asians was also characterized by increased abdominal fatness, greater insulin resistance and hyperinsulinemia, higher CRP, lower adiponectin, dyslipidemia (high LDL, high TGL, low HDL), and increased coronary artery disease [29] [49]. Insulin resistance was more frequent than impaired insulin secretion in T2DM individuals with the Asian phenotype. In contrast, impaired insulin secretion was more frequent than insulin resistance in the European T2DM phenotype [49]. Unfortu- 
nately, information on insulin secretion/resistance measures was not available for the Zapotec sample in this study.

Phenotypic differences between Asian and European T2DM individuals included weight, BMI and fat distribution [50]. The "Asian T2DM phenotype" was characterized by normal weight, BMI and height in conjunction with central obesity and thin limbs [51]. In contrast to the present study, another sample of adult Zapotecs with T2DM had, on average, a BMI that was elevated compared to non-T2DM individuals and an increased frequency of obesity [39]. These individuals may not have advanced stages of T2DM.

The T2DM phenotype observed in indigenous Zapotec women and men was similar to the Asian T2DM phenotype, which is consistent with the genetic history of indigenous people in Mesoamerica [52] who were derived from prehistoric Asian migrants via the Bering Strait land bridge [53].

Reduced grip strength has been associated with T2DM in several studies [54] [55] [56] [57]. In addition, risk of sarcopenia was associated with increased insulin resistance, and the risk exceeded the normal degree of age-associated decline in muscle strength and muscle mass [54] [58]. Sarcopenia is strongly associated with poor outcomes (e.g., cardiovascular, microvascular, nephropathy) in T2DM [59]. Reduction in insulin signaling apparently triggers decreased protein synthesis and increased protein degradation resulting in reduced muscle mass [60]. Higher $\mathrm{HbAlc}$ is also correlated with greater age-associated decrease in muscle strength [20]. Hyperglycemia negatively affected muscular strength and quality, but not muscle mass in the Baltimore Longitudinal Study [42]. Sarcopenia among subjects in the present investigation may signal that these individuals had an advanced form of T2DM as they died within 10 years of being surveyed in 2000 .

The two significant observations in the present study of indigenous Zapotec women and men merit attention. T2DM individuals were characterized by 1) reduced muscular strength (grip strength) and mass (EAMC), and 2) increased central adiposity (waist: hip ratio), and 3) normal or greater height. Although muscular strength and muscularity declined with age among Zapotec women and men as in other populations, [36] reduced grip strength also characterized individuals with T2DM as in several other studies [54] [55] [56] [57]. Increased central adiposity was characteristic of T2DM in individuals across several ethnicities, e.g., Asian, African American, European American and Hispanic American [60] [61] [62]. In the present analysis, loss of muscle mass and decrease in strength was significantly greater in T2DM women and men.

Central adiposity was also a more specific predictor of T2DM than the BMI as an elevated BMI was associated with T2DM in non-Hispanic American Whites, but was not associated with T2DM among Asians [49]. The lack of an association between an elevated BMI and T2DM among Asians has given rise to the notion of an "Asian Indian Phenotype" which has also been labeled as the Thin-Fat Asian Indian phenotype for T2DM [63]. The Asian Indian T2DM phenotype is 
characterized by normal weight and BMI, thin limbs (i.e., reduced extremity skinfolds and muscle mass), and a significantly increased waist: hip ratio [64]. The lower BMI, hip circumference, and triceps skinfold in the indigenous Zapotec women with T2DM appeared to align with the Asian Indian T2DM phenotype.

Several important limitations of the present study should be noted. First, a major limitation is reliance on T2DM-related mortality as no diabetes testing was done in this survey. It is likely T2DM subjects are in the comparison group, causing a bias toward the null hypothesis (i.e., no differences between the two groups) and underestimate T2DM effects. In addition, prior studies in the Valley of Oaxaca in Zapotec and Mixe Indians used biochemical diagnostics found an under ascertainment of T2DM as high as 70\% [39]. Secondly, the sample size of T2DM subjects was small, 20 females and 8 males; this was ameliorated to some extent with bootstrapping (resampling) analyses. And third, only anthropometric characteristics and cause of death from death records were available for analysis, whereas many significant phenotypic markers of T2DM are clinical chemistry measures.

In the final analysis, the risk for T2DM was associated with reduced estimated muscle mass (increased sarcopenia) and grip strength, and with central adiposity in this small sample of Zapotec (Amerindian) women and men from a small genetic isolate who died $<10$ years after the anthropometric survey. The characteristics of Zapotec women and men with T2DM were very similar to the Asian T2DM phenotype, which is reasonable given the Asian genetic heritage of indigenous peoples of the Americas. Increased BMI and sitting height were not associated with T2DM, also consistent with the Asian T2DM phenotype. The Zapotec female and male T2DM phenotype was, thus, characterized by normal height and proportions, reduced appendicular adiposity, increased central obesity, and reduced muscle mass and strength compared to women and men without T2DM. In summary, the T2DM phenotype derived from the present analysis may better predict T2DM mortality than T2DM per se. Therefore, in populations of Amerindian heritage, the Asian T2DM phenotype is more appropriate than the diabetes European phenotype. Future studies of T2DM in Amerindian indigenous populations should consider the Asian Fat-Thin T2DM phenotype as it seems more appropriate based upon indigenous population origins.

\section{Acknowledgments}

The research upon which this study is based was supported in part by grants from the National Science Foundation (BNS 78-10641, 1978-1980; BCS 9816400, 1999-2002) and from the Institute of Latin American Studies at the University of Texas at Austin.

\section{Conflicts of Interest}

The authors declare no conflicts of interest regarding the publication of this paper. 


\section{References}

[1] Dahlberg, G. (1949-1950) Obesity and Diabetes. Acta Genetica et Statistica Medica, 1, 343-354. https://doi.org/10.1159/000150656

[2] Keys, A., Fidanza, F., Karvonen, M.J., Kimura, N. and Taylor, H.L. (1972) Indices of Relative Weight and Obesity. Chronic Diseases, 25, 329-343. https://doi.org/10.1016/0021-9681(72)90027-6

[3] Vernet, A. (1954) Diabetes Due to Adipose Encumberment. Revue Medicale de la Suisse Romande, 74, 624-630.

[4] Keen, H., Jarrett, R.J., Thomas, B.J. and Fuller, J.H. (1979) Diabetes, Obesity and Nutrition: Epidemiological Aspects. In: Diabetes and Obesity, Excerpta Medica, Amsterdam, 91-103.

[5] Keen, H., Thomas, B.J., Jarrett, R.J. and Fuller, J.H. (1979) Nutrient Intake, Adiposity, and Diabetes. British Medical Journal, 1, 655-658.

https://doi.org/10.1136/bmj.1.6164.655

[6] Weyer, C., Funahashi, T., Tanaka, S., Hotta, K., Matsuzawa, K., Pratley, R.E. and Tataranni, P.A. (2001) Hypoadiponectinemia in Obesity and Type 2 Diabetes: Close Association with Insulin Resistance and Hyperinsulinemia. Clinical Endocrinology \& Metabolism, 86, 1930-1935. https://doi.org/10.1210/jcem.86.5.7463

[7] Forrester, T., Ghosh, K., Lanceta, J. and Little, B.B. (2017) A Pilot Study of Type 2 Diabetes among Female Jamaican Maroons from a Genetic Isolate: Physical Characteristics and Prevalence. International Journal of Diabetes \& Clinical Diagnosis, 4, 125. https://doi.org/10.15344/2394-1499/2017/125

[8] Haffner, S.M., Stern, M.P., Hazuda, H.P., Pugh, J. and Patterson, J.K. (1987) Do Upper-Body and Centralized Adiposity Measure Different Aspects of Regional Body-Fat Distribution? Relationship to Non-Insulin-Dependent Diabetes Mellitus, Lipids, and Lipoproteins. Diabetes, 36, 43-51. https://doi.org/10.2337/diabetes.36.1.43

[9] Butler, W.J., Ostrander, L.D., Carman, W.J. and Lamphiear, D.E. (1982) Diabetes Mellitus in Tecumseh, Michigan. Prevalence, Incidence, and Associated Conditions. American Journal of Epidemiology, 116, 971-980. https://doi.org/10.1093/oxfordjournals.aje.a113499

[10] Dinh, A., Miertschin, S., Young, A. and Mohanty, S.D. (2019) A Data-Driven Approach to Predicting Diabetes and Cardiovascular Disease with Machine Learning. BMC Medical Informatics and Decision Making, 19, 211. https://doi.org/10.1186/s12911-019-0918-5

[11] Weitzman, S., Wang, C.H., Pankow, J.S., Schmidt, M.I. and Brancati, F.L. (2010) Are Measures of Height and Leg Length Related to Incident Diabetes Mellitus? The ARIC (Atherosclerosis Risk in Communities) Study. Acta Diabetologica, 47, 237-242. https://doi.org/10.1007/s00592-009-0145-0

[12] Danquah, I., Addo, J., Boateng, D., Klipstein-Grobusch, K., Meeks, K., Galbete, C., Beune, E., Bahendeka, S., Spranger, J., Mockenhaupt, F.P. and Stronks, K. (2019) Early-Life Factors Are Associated with Waist Circumference and Type 2 Diabetes among Ghanaian Adults: The RoDAM Study. Scientific Reports, 9, Article No. 10848. https://doi.org/10.1038/s41598-019-47169-6

[13] Wittenbecher, C., Kuxhaus, O., Boeing, H., Stefan, N. and Schulze, M.B. (2019) Associations of Short Stature and Components of Height with Incidence of Type 2 Diabetes: Mediating Effects of Cardiometabolic Risk Factors. Diabetologia, 62, 2211-2221. https://doi.org/10.1007/s00125-019-04978-8 
[14] Mueller, N.T., Duncan, B.B., Barreto, S.M., Chor, D., Vigo, A., Aquino, E.M.L., Demerath, E.W. and Schmidt, M.I. (2015) Relative Leg Length Is Associated with Type 2 Diabetes Differently According to Pubertal Timing: The Brazilian Longitudinal Study of Adult Health. American Journal of Human Biology, 27, 219-225. https://doi.org/10.1002/ajhb.22641

[15] Johnston, L.W., Harris, S.B., Retnakaran, R., Gerstein, H.C., Zinman, B., Hamilton, J. and Hanley, A.J. (2013) Short Legs, a Marker of Early Childhood Deprivation, Is Associated with Metabolic Disorders Underlying Type 2 Diabetes. The Promise Cohort Study. Diabetes Care, 36, 3599-3606. https://doi.org/10.2337/dc13-0254

[16] Demerath, E.W., Sun, S.S., Rogers, N., Lee, M., Reed, D., Choh, A.C., Couch, W., Czerwinski, S.A., Chumlea, W.C., Siervogel, R.M. and Towne, B. (2007) Anatomical Patterning of Visceral Adipose Tissue: Race, Sex, and Age Variation. Obesity, 15, 2984-2993. https://doi.org/10.1038/oby.2007.356

[17] Mohan, V., Sandeep, S., Deepa, R., Shah, B. and Varghese, C. (2007) Epidemiology of Type 2 Diabetes: Indian Scenario. Indian Journal of medical Research, 125, 217.

[18] Hu, H., Huff, C.D., Yamamura, Y., Wu, X.F. and Strom, S.S. (2015) The Relationship between Native American Ancestry, Body Mass Index and Diabetes Risk among Mexican-Americans. PLoS ONE, 10, e0141260.

https://doi.org/10.1371/journal.pone.0141260

[19] Eller, N.T., Duncan, B.B., Barreto, S.M., Chor, D., Vigo, A., Aquino, E.M.L., Demerath, E.W. and Schmidt, M.I. (2015) Relative Leg Length Is Associated with Type 2 Diabetes Differently According to Pubertal Timing: The Brazilian Longitudinal Study. American Journal of Human Biology, 27, 219-225. https://doi.org/10.1002/ajhb.22641

[20] Asao, K., Kao, W.L., Baptiste-Roberts, K., Bandeen-Roche, K., Erlinger, T.P. and Brancati, F.L. (2006) Short Stature and the Risk of Adiposity, Insulin Resistance, and Type 2 Diabetes in Middle Age. Diabetes Care, 29, 1632-1637. https://doi.org/10.2337/dc05-1997

[21] Malina, R.M., Peña Reyes, M.E. and Little, B.B. (2010) Secular Change in Heights of Indigenous Adults from a Zapotec-Speaking Community in Oaxaca, Southern Mexico. American Journal of Physical Anthropology, 141, 463-475. https://doi.org/10.1002/ajpa.21167

[22] Little, B.B. and Malina, R.M. (1989) Genetic Drift and Natural Selection in an Isolated Zapotec-Speaking Community in the Valley of Oaxaca, Southern Mexico. Human Heredity, 39, 99-106. https://doi.org/10.1159/000153842

[23] Little, B.B. and Malina, R.M. (2005) Inbreeding Avoidance in an Isolated Indigenous Zapotec Community in the Valley of Oaxaca, Southern Mexico. Human Biology, 77, 306-316. https://doi.org/10.1353/hub.2005.0049

[24] Little, B.B., Reyes, M.P. and Malina, R.M. (2006) Opportunity for Natural Selection and Gene Flow in an Isolated Zapotec-Speaking Community in Southern Mexico in the Throes of a Secular Increase in Size. Human Biology, 78, 295-305.

https://doi.org/10.1353/hub.2006.0047

[25] Little, B.B., Malina, R.M. and Reyes, M.E.P. (2008) Natural Selection and Demographic Transition in a Zapotec-Speaking Genetic Isolate in the Valley of Oaxaca, Southern Mexico. Annals of Human Biology, 35, 34-49.

https://doi.org/10.1080/03014460701769808

[26] Malina, R.M., Little, B.B., Buschang, P.H., DeMoss, J. and Selby, H.A. (1985) Socioeconomic Variation in the Growth Status of Children in a Subsistence Agricultural Community. American Journal of Physical Anthropology, 68, 385-391. https://doi.org/10.1002/ajpa.1330680309 
[27] Little, B.B., Peña Reyes, M.E. and Malina, R.M. (2017) Natural Selection and Type 2 Diabetes-Associated Mortality in an Isolated Indigenous Community in the Valley of Oaxaca, Southern Mexico. American Journal of Physical Anthropology, 162, 561-572. https://doi.org/10.1002/ajpa.23139

[28] Martinez-Julian, S., Hernandez-Barroso, G. and Canseco-Pacheco, M.T. (2001) Diagnostico de Salud 2001 (Servicios de Salud de Oaxaca, Jurisdiccion Sanitaria No. 1, Valles Centrales, Santo Tomas Mazaltepec, Oaxaca, Mexico).

[29] Malina, R.M., Peña Reyes, M.E., Tan, S.K., Buschang, P.H., Little, B.B. and Kozieł, S. (2004) Secular Change in Height, Sitting Height and Leg Length in Rural Oaxaca, Southern Mexico: 1968-2000. Annals of Human Biology, 31, 615-633.

https://doi.org/10.1080/03014460400018077

[30] Malina, R.M., Peña Reyes, M.E., Tan, S.K. and Little, B.B. (2004) Secular Change in Age at Menarche in Rural Oaxaca, Southern Mexico: 1968-2000. Annals of Human Biology, 31, 634-646. https://doi.org/10.1080/03014460400018085

[31] Malina, R.M., Peña Reyes, M.E., Tan, S.K., Buschang, P.H. and Little, B.B. (2007) Overweight and Obesity in a Rural Amerindian Population in Oaxaca, Southern Mexico: 1968-2000. American Journal of Human Biology, 19, 711-721.

https://doi.org/10.1002/ajhb.20622

[32] Peña Reyes, M.E., Tan, S.K. and Malina, R.M. (2004) Urban-Rural Contrasts in the Growth Status of School Children in Oaxaca, Mexico. Annals of Human Biology, 30, 693-713. https://doi.org/10.1080/03014460310001612792

[33] Lohman, T.G., Roche, A.F. and Martorell, R. (1988) Anthropometric Standardization Reference Manual. Human Kinetics, Champaign.

[34] Malina, R.M. (1995) Anthropometry. In: Maud, P.J. and Foster, C., Eds., Physiological Assessment of Human Fitness, Human Kinetics, Champaign, 205-219.

[35] Malina, R.M., Peña Reyes, M.E., Alvarez, C.G. and Little, B.B. (2011) Age and Secular Effects on Muscular Strength of Indigenous Rural Adults in Oaxaca, Southern Mexico: 1978-2000. Annals of Human Biology, 38, 175-187. https://doi.org/10.3109/03014460.2010.504196

[36] Conway, B.N., Shu, X.-O., Zhang, X., Xiang, Y.-B., Cai, H., Li, H., Li, H., Yang, G., Gao, Y.T. and Zheng, W. (2012) Age at Menarche, the Leg Length to Sitting Height Ratio, and Risk of Diabetes in Middle-Aged and Elderly Chinese Men and Women. PLOS ONE, 7, e30625. https://doi.org/10.1371/journal.pone.0030625

[37] Stein, A.D., Obrutu, O.E., Behere, R.V. and Yajnik, C.S. (2019) Developmental Undernutrition, Offspring Obesity and Type 2 Diabetes. Diabetologia, 27, 1-6. https://doi.org/10.1007/s00125-019-4930-1

[38] Escobedo, J., Chavira, I., Martínez, L., Velasco, X., Escandón, C. and Cabral, J. (2010) Diabetes and Other Glucose Metabolism Abnormalities in Mexican Zapotec and Mixe Indians. Diabetic Medicine, 27, 412-416. https://doi.org/10.1111/j.1464-5491.2010.02966.x

[39] Jang, H.C. (2016) Sarcopenia, Frailty, and Diabetes in Older Adults. Diabetes \& Metabolism Journal, 40, 182-189. https://doi.org/10.4093/dmj.2016.40.3.182

[40] Morley, J.E., Malmstrom, T.K., Rodriguez-Manas, L., et al. (2014) Frailty Is Also Higher in the Prevalence in Older with DM. Journal of the American Medical Directors Association, 15, 853-859. https://doi.org/10.1016/j.jamda.2014.10.001

[41] Kalyani, R.R., Metter, E.J., Egan, J., et al. (2015) Hyperglycemia Predicts Persistently Lower Muscle Strength with Aging. Diabetes Care, 38, 82-90.

https://doi.org/10.2337/dc14-1166

[42] Umegaki, H. (2015) Sarcopenia and Diabetes: Hyperglycemia Is a Risk Factor for 
Age-Associated Muscle Mass and Functional Reduction. Journal of Diabetes Investigation, 6, 623-624. https://doi.org/10.1111/jdi.12365

[43] Baumgartner, R.N., Koehler, K.M., Gallagher, D., Romero, L., Heymsfield, S.B., Ross, R.R., Garry, P.J. and Lindeman, R.D. (1998) Epidemiology of Sarcopenia among the Elderly in New Mexico. American Journal of Epidemiology, 147, 755-763. https://doi.org/10.1093/oxfordjournals.aje.a009520

[44] Androga, L., Sharma, D., Amodu, A. and Abramowitz, M.K. (2017) Sarcopenia, Obesity, and Mortality in US Adults with and without Chronic Kidney Disease. Kidney International Reports, 2, 201-211. https://doi.org/10.1016/j.ekir.2016.10.008

[45] Schulze, M.B., Heideman, C., Schienkiewitz, A., Bergman, M.M., Hoffman, K. and Boeing, H. (2006) Comparison of Anthropometric Characteristics in Predicting the Incidence of Type 2 Diabetes in the EPIC Potsdam Study. Diabetes Care, 29, 1921-1923. https://doi.org/10.2337/dc06-0895

[46] Bhupathiraju, S.N. and Hu, F.B. (2016) Epidemiology of Obesity and Diabetes and Their Cardiovascular Complications. Circulation Research, 118, 1723-1735. https://doi.org/10.1161/CIRCRESAHA.115.306825

[47] Ma, R.C. and Chan, J.C. (2013) Type 2 Diabetes in East Asians: Similarities and Differences with Populations in Europe and the United States. Annals of the New York Academy of Sciences, 1281, 64-91. https://doi.org/10.1111/nyas.12098

[48] Unnikrishnan, R., Anjana, R.M. and Mohan, V. (2014) Diabetes in South Asians: Is the Phenotype Different? Diabetes, 63, 53-55. https://doi.org/10.2337/db13-1592

[49] Bakker, L.E.H., Sleddering, M.A., Schoones, J.W., Meinders, A.E. and Jazet, I.M. (2013) Pathogenesis of Type 2 Diabetes in South Asians. European Journal of Endocrinology, 169, R99-R114. https://doi.org/10.1530/EJE-13-0307

[50] Chan, J.C.N., Yeung, R. and Luk, A. (2014) The Asian Diabetes Phenotypes: Challenges and Opportunities. Diabetes Research and Clinical Practice, 105, 135-139. https://doi.org/10.1016/j.diabres.2014.05.011

[51] Sanchez-Pozos, K. and Menjivar, M. (2016) Genetic Component of Type 2 Diabetes in a Mexican Population. Archives of Medical Research, 27, 496-505. https://doi.org/10.1016/j.arcmed.2016.12.007

[52] Reich, D., Patterson, N., Campbell, D., Tandon, A., Mazieres, S., Ray, N., Parra, M.V., Rojas, W., Duque, C., Mesa, N. and García, L.F. (2012) Reconstructing Native American Population History. Nature, 488, 370-374.

[53] Cetinus, E., Buyukbese, M.A., Uzel, M., Ekerbicer, H. and Karaoguz, A. (2005) Hand Grip Strength in Patients with Type 2 Diabetes Mellitus. Diabetes Research and Clinical Practice, 70, 278-286. https://doi.org/10.1016/j.diabres.2005.03.028

[54] Ntuk, U.E., Celis-Morales, C.A., Mackay, D.F., Sattar, N., Pell, J.P. and Gill, J.M.R. (2017) Association between Grip Strength and Diabetes Prevalence in Black, South-Asian, and White European Ethnic Groups: A Cross-Sectional Analysis of 418656 Participants in the UK Biobank Study. Diabetic Medicine, 34, 1120-1128. https://doi.org/10.1111/dme.13323

[55] Shafiee, G., Keshtkar, A., Soltani, A., Ahadi, Z., Larijani, B. and Heshmat, R. (2017) Prevalence of Sarcopenia in the World: A Systematic Review and Meta-Analysis of General Population Studies. Journal of Diabetes \& Metabolic Disorders, 16, 21. https://doi.org/10.1186/s40200-017-0302-x

[56] Leenders, M., Verdijk, L.B., van der Hoeven, L., Adam, J.J., van Kranenburg, J., Nilwik, R. and van Loon, L.J. (2013) Patients with Type 2 Diabetes Show a Greater Decline in Muscle Mass, Muscle Strength, and Functional Capacity with Aging. Journal of the American Medical Directors Association, 14, 585-592. 
https://doi.org/10.1016/j.jamda.2013.02.006

[57] Kim, T.N., Park, M.S., Yang, S.J., Yoo, H.J., Kang, H.J., Song, W., Seo, J.A., Kim, S.G., Kim, N.H., Baik, S.H. and Choi, D.S. (2010) Prevalence and Determinant Factors of Sarcopenia in Patients with Type 2 Diabetes. Diabetes Care, 33, 1497-1499. https://doi.org/10.2337/dc09-2310

[58] Bakker, L.E., van Schinkel, L.D., Guigas, B., Streefland, T.C., Jonker, J.T., van Klinken, J.B., van der Zon, G.C., Lamb, H.J., Smit, J.W., Pijl, H. and Meinders, A.E. (2014) A 5-Day High-Fat, High-Calorie Diet Impairs Insulin Sensitivity in Healthy, Young South Asian Men But Not in Caucasian Men. Diabetes, 63, 248-258. https://doi.org/10.2337/db13-0696

[59] Leong, D.P., Teo, K.K., Rangarajan, S., Lopez-Jaramillo, P., Avezum, A., Orlandini, A., Seron, P., Ahmed, S.H., Rosengren, A., Kelishadi, R. and Rahman, O. (2015) Prognostic Value of Grip Strength: Findings from the Prospective Urban Rural Epidemiology (PURE) Study. The Lancet, 386, 266-273.

https://doi.org/10.1016/S0140-6736(14)62000-6

[60] Alberti, G., Zimmet, P., Shaw, J., Bloomgarden, Z., Kaufman, F. and Silink, M. (2004) Type 2 Diabetes in the Young: The Evolving Epidemic. Diabetes Care, 27, 1798-1811. https://doi.org/10.2337/diacare.27.7.1798

[61] Tuomi, T., Santoro, N., Caprio, S., Cai, M., Weng, J. and Groop, L. (2014) The Many Faces of Diabetes: A Disease with Increasing Heterogeneity. The Lancet, 383, 1084-1094. https://doi.org/10.1016/S0140-6736(13)62219-9

[62] Hardy, D.S., Stallings, D.T., Garvin, J.T., Xu, H. and Racette, S.B. (2017) Best Anthropometric Discriminators of Incident Type 2 Diabetes among White and Black Adults: A Longitudinal ARIC Study. PLoS ONE, 12, e0168282. https://doi.org/10.1371/journal.pone.0168282

[63] Banerji, M.A., Faridi, N., Atluri, R., Chaiken, R.L. and Lebovitz, H.E. (1999) Body Composition, Visceral Fat, Leptin, and Insulin Resistance in Asian Indian Men. The Journal of Clinical Endocrinology \& Metabolism, 84, 137-144. https://doi.org/10.1210/jc.84.1.137

[64] Ruderman, N., Chisholm, D., Pi-Sunyer, X. and Schneider, S. (1998) The Metabolically Obese, Normal-Weight Individual Revisited. Diabetes, 47, 699-713. https://doi.org/10.2337/diabetes.47.5.699 